Revista Mexicana de Economía y Finanzas Nueva Época

Volumen 14 Primer Número Especial Aniversario, Agosto 2019, pp. 601-616

DOI: https://doi.org/10.21919/remef.v14i0.425

\title{
Active portfolio management in the Andean countries' stock markets with Markov-Switching GARCH models
}

\author{
Oscar V. De la Torre-Torres ${ }^{1}$ \\ Universidad Michoacana de San Nicolás de Hidalgo, Mexico \\ Dora Aguilasocho-Montoya ${ }^{2}$ \\ Universidad Michoacana de San Nicolás de Hidalgo, Mexico \\ José Álvarez-García ${ }^{3}$ \\ Universidad de Extremadura, España
}

(Recepción: 2/abril/2019, aceptado: 8/julio/2019)

\section{Abstract}

In the present paper we test the benefits of using two-regime Markov-Switching (MS) models in the stock markets of the MSCI Andean index (Chile, Colombia and Perú). We tested this with either, constant, ARCH or GARCH variances and Gaussian or t-Student log-likelihood functions. By performing 996 weekly simulations from January 2000 to January 2019 with each MS model, we tested the next investment strategy for a U.S. dollar based investor: 1) to invest in the risk-free asset if the probability of being in the high-volatility regime at $t+1$ is higher than $50 \%$ or 2 ) to do it in the stock market index otherwise. Our results suggest that the Gaussian MS-GARCH models are the most suitable to generate alpha in the Chilean stock market and the Gaussian MS-ARCH in the Colombian one. For the Peruvian case, we found that is preferable to perform passive investing instead of active trading.

JEL Classification: C580, G11, G170

Keywords: Markov-Switching GARCH, Markov chain processes, Active portfolio management, Andean region stocks, Computational Finance, Risk management.

\section{Administración activa de portafolios con modelos markovianos de cambio de régimen-GARCH en los principales países de la región andina}

\section{Resumen}

En el presente trabajo se estudia el empleo de modelos markovianos con cambio de régimen (Markov-Switching, $\mathrm{MS}$ ) de dos regímenes. Estos con varianza constante, ARCH o GARCH, así como con probabilidad gaussiana o t-Student. Los mismos se utilizaron para administrar activamente portafolios en los mercados accionarios andinos (Chile, Colombia y Perú). Al simular 996 semanas de enero del 2000 a enero del 2019, se ejecutó la siguiente estrategia de inversión en dólares de los EEUU: 1) invertir en el activo libre de riesgo si la probabilidad de estar en el régimen de alta volatilidad en $t+1$ es mayor a $50 \%$ o 2) invertir en el índice accionario en caso contrario. Los resultados sugieren que emplear modelos MS-GARCH gaussianos es lo mejor para la administración activa en el mercado chileno, que el modelo MS-ARCH gaussiano lo es en el colombiano y que es preferible la administración pasiva en Perú.

\footnotetext{
${ }^{1}$ ORCID: 0000-0001-9281-974X

e-mail: oscar.delatorre.torres@gmail.com

${ }^{2}$ e-mail: amontoya@umich.mx

${ }^{3}$ ORCID: 0000-0002-0056-5488

e-mail: pepealvarez@unex.es

*Sin fuente de financiamiento declarada para el desarrollo de la investigación
} 


\section{Resumen}

Clasificación JEL: C580, G11, G170

Palabras clave: Markov-Switching GARCH, Cadenas markovianas, Administración activa de portafolios, Acciones de la región Andina, Finanzas computacionales, Administración de riesgos.

\section{Introduction and literature review}

Among the most relevant tasks in risk measurement and portfolio management activities, is the proper expected return and risk exposure parameters. This has been done since the seminal proposal of Markowitz (1959, 1952). In order to measure the portfolio's expected return, several methods have been used, such as the arithmetic or exponential mean and even some more robust factor mean methods (Alexander, 2002, Ang \& Bekaert, 2002a, Sharpe, 1963, 1964). In these last models, the expected return is not a fixed, but timevarying parameter.

Some other extensions to the expected mean can be found with the use of the ARMA ${ }^{4}$ or ARMAX models, in which the stochastic process that generates the return time series $\left(r_{t}\right)$ is determined given the past (lagged) values of the returns and also the lagged values of the residuals $\left(\varepsilon_{t}\right)$. Also, if it is necessary to the analyst, in this model can be included the values of other non-lagged exogenous factors such as social or Economic variables $\left(x_{k, t}\right)$ :

$$
r_{t}=\alpha+\sum_{p=1}^{P} \beta_{p} \cdot r_{t-p}+\sum_{q=1}^{Q} \gamma_{p} \cdot \varepsilon_{t-q}+\sum_{k=1}^{K} \lambda_{k} \cdot x_{k, t}+\varepsilon_{t}
$$

As a methodological note, in the present paper we will follow the Financial Econometrics and asset pricing practice of measuring the returns at $t\left(r_{t}\right)$ with the continuous time method as follows:

$$
r_{t}=\ln \left(P_{t}\right)-\ln \left(p_{t-1}\right)
$$

Given the expected return $(\mu)$ calculation, either with an unconditional mean or a conditional one, such as a factor, ARMAX or the ARMA one in (1), it is of interest for the investor to proxy the risk exposure. A departing method is the "conventional" or constant variance method $\left(\sigma_{t}^{2}=\sum_{t=1}^{T}\left(r_{t}-\mu\right) \cdot N^{-1}\right)$ with a fixed value at $\mathrm{t}$. Following this method and as an extension to the rationale of the ARMA models, such as (1), Engle (1982) and Bollerslev (1987) made a significant breakthrough with their time varying GARCH $^{5}$ model:

$$
\sigma_{t}^{2}=\sigma_{0}+\sum_{p=1}^{P} \beta_{p} \cdot \varepsilon_{t-p}^{2}+\sum_{q=1}^{Q} \gamma_{p} \cdot \sigma_{t-q}^{2}+\nu_{t}
$$

In the previous expression, the variance $\left(\sigma_{t}^{2}\right)$ value at $t$ is determined with the lagged squared residuals of the mean value $(\mathrm{ARCH}$ term) and the lagged values of the variance $\left(\sigma_{t-q}^{2}\right)$ in (3). This last term is known as the GARCH term. Departing from this, (3) is an ARCH model when its functional form is $\sigma_{t}^{2}=\sigma_{0}+\sum_{p=1}^{P} \beta_{p} \cdot \varepsilon_{t}^{2}$ or a GARCH one when all the terms in (3) are used.

Given the time varying features of the GARCH model, several improvements in asset pricing and risk measurement were developed in the Financial industry. This is in order to determine either a proper asset pricing valuation for investment purposes or the proper

\footnotetext{
${ }^{4}$ We will use the following acronyms for these models: ARMA for the Auto Regressive Moving Average model and ARIMA for the Auto Regressive Integrated Moving Average model.

${ }^{5}$ Acronym of Generalized Auto Regressive Conditional Heteroskedasticity model.
} 
risk measurement for capital adequacy practices. This type of model lead to more reliable and fitted values of the risk exposure during distress time periods. Departing from the symmetric GARCH rationale of (3), several extensions for asymmetric or leverage effects have been made. Among the most used and well-known, we can mention the EGARCH model of Nelson (1991) or the GJR-GARCH of Glosten, Jaganathan and Runkle (1993). Also, the extensions have been made in the log-likelihood function (LLF) by using other probability density functions such as the t-Student, the asymmetric t-Student or the generalized error distribution.

An interesting result that departs from (4) if the fact that the sum $\sum_{p=1}^{P} \beta_{p}+\sum_{q=1}^{Q} \gamma_{p}$ lead to a concept known as "persistence". This concept means that, if $\sum_{p=1}^{P} \beta_{p}+\sum_{q=1}^{Q} \gamma_{p} \approx$ 1 , the high volatility levels observed at $t$, will persist in longer future time periods, an issue that is proper of the behavior of the return time series of financial assets. Among the most relevant explanations to this issue, we mention the works of Dueker (1997), Lamoureoux and Lastrapes (1990); Hamilton and Susmel (1994), Klaassen (2002) and Hass, Mitnik and Paolella (2004) who suggest that the high persistence is due to the fact that the stochastic process must be modeled with multimodal probability density functions in which there are $=1,2, \ldots, \mathrm{S}$ regimes or states of nature, also in which there are s location (expected return) and s scale (risk exposure or variance) parameters.

Departing form the seminal proposal of the Markov-Switching (henceforth MS) models of Hamilton (1989, 1994), the expected return (mean) and risk exposure (variance) can be estimated for $\mathrm{S}$ states. Departing from this rationale, an ARMA model, such as (1), can be expressed as a MS-ARMA model as follows:

$$
r_{t}=\alpha_{s}+\sum_{p=1}^{P} \beta_{p, s} \cdot r_{t-p}+\sum_{q=1}^{Q} \gamma_{p, s} \cdot \varepsilon_{t-1}+\varepsilon_{t}
$$

Given the parameter vector $\theta=\left[\alpha_{s}, \beta_{s}, \gamma_{s}\right]$, the MS model has some extra parameters or outputs in $\theta$, such as the smoothed probability $\xi_{s, t}$ of being in the $S$ at $t$. This along with the transition probabilities $\left(\pi_{i, j}=P\left(s_{t}=i \mid s_{t-1}=j, \theta, r_{t}\right), \theta=\left[\alpha_{s}, \beta_{s}, \gamma_{s}, \sigma_{s}^{2}, \xi_{s, t}\right]\right)$ of transiting from one regime $s=i$ at $t$, to another one $s=j$ in $t+1$. As noted, this behavior is one of a latent or unobservable Markovian chain (first order Markovian chain) and these transition probabilities can be arranged in a transition probability matrix $\Pi$ :

$$
\boldsymbol{\Pi}=\left[\begin{array}{c}
\pi_{i, i} \& \ldots \& \pi_{j, i} \\
\vdots \& \vdots \vdots \\
\pi_{i, j} \& \ldots \& \pi_{j, j}
\end{array}\right]
$$

One limitation of the MS model in (5) is that it assumes that the variance in each regime is fixed trough time. Departing from this assumption, Hamilton y Susmel (1994), Klaassen (2002) and Haas, Mitnik and Paolella (2004) propose to extend the GARCH model in (4) to a s regime version. That is, they propose and developed the mathematical foundations of a Markov-Switching GARCH (MS-GARCH) model as the general form of the next expression:

$$
\sigma_{t}^{2}=\sigma_{0, s}+\sum_{p=1}^{P} \beta_{p, s} \cdot \varepsilon_{t-p}^{2}+\sum_{q=1}^{Q} \gamma_{p, s} \cdot \sigma_{t-q}^{2}+\nu_{t}
$$

Given their dynamic nature, their smoothed probabilities of being in a given s regime at $t$ and their transition probabilities, MS models have been used in several applications. Among these, we find the crisis time periods identification and spillover effects in financial markets. With this rationale, we found the works of Ang and Bekaert (2002b, 2002c), 
Kritzman, Page and Turkington (2012), Klein (2013), Areal, Cortez and Silva (2013), Zheng y Zuo (2013), and the one of Hauptmann et. al. (2014) (among others) who test the use of MS models to estimate the performance of stock markets in developed countries such as France, Germany, Japan, Switzerland, the U.K., or the U.S. In their results, they found evidence in favor of using two or three regime MS models. In other type of securities, Alexander and Kaeck (2007), Castellano and Scacia (2014) and Ma, Deng and Ho (2018) study the appropriateness of the use of MS models in credit default swaps (CDS) and their spillover effect in FX, stock or oil markets.

For the review of the use of MS models in Emerging countries' stock markets, we mention the work of Zhao (2010), Walid et. al. (2011), Walid and Duc Khuong (2014), the one of Rotta and Valls-Pereira (2016), Mouratidis et. al. (2013), Miles and Vijverberg (2011); Lopes and Nunes (2012), Kanas (2005), Álvarez-Plata and Schrooten (2006), Parikakis and Merika (2009), Girdzijauskas (2009), Dubinskas and Stungurienè (2010); Kutty (2010), Dufrénot, Mignon and Péguin-Feissolle (2011) y Ahmed et. al. (2018). These Works found appropriate the use of MS models in the stochastic process of these markets, along with the application of these to measure the spillover effect in FX (given the monetary policy decisions) and stock markets.

Complementary to the previous works and of special interest for the present paper, we found the works of Brooks and Persand (2001), Ang and Bekaert (2002b, 2002c), Kritzman, Page and Turkington (2012), Hauptmann et. al. (2014) and De la Torre, Galeana and Álvarez-García (2018). These papers study the application of MS models in active portfolio management decisions, against a buy and hold or passive investment (index replication) strategy.

The rationale behind the investment decision with the use of MS models is found in Brooks and Persand (2001) and Ang and Bekaert (2002b, 2002c). These authors use the active investment strategy in stock indexes of developing countries such as the U.S. and the U.K., along with the use of these in internationally diversified portfolios, given the use of a MS covariance matrix.

Following these two works, we found the results of Kritzman, Page and Turkington (2012), Hauptmann et. al. (2014) and De la Torre, Galeana and Álvarez-García (2018) closely related to the present paper. The last work test, in part, the application of MS models in the investment process of emerging stock markets (Mexico).

With this brief literature review, we found the next research topics of interest to develop herein:

1. The works in the previous literature review do not study the use of MS-ARCH or MS-GARCH models for investment decisions.

2. The Emerging markets studied in the previous works are focused in Brazil, Mexico or other non-Latin American markets, setting aside the study of the use of MS models in the markets of the Andean region. Those that belong to the MSCI Andean index (Chile, Colombia and Peru).

3. Little has been written in the countries of interest about the benefits of using MS, MS-ARCH or MS-GARCH models in these Andean countries. As an example, the works of Camacho y Pérez-Quirós (2014), Cabrera et. al. (2017) y Sosa, Ortiz and Cabello (2018) make an interesting review of the use of MS-GARCH models with two or three regimes, being Cabrera et. al. (2017) the only work who test the use of MS-GARCH models.

Departing from these reviews of interest, we want to extend these and their results about the use of MS-GARCH models for investment purposes in these countries (the Andean ones). Our main interest is to probe that the use of either MS-ARCH or MSGARCH models, from a U.S. dollar-based investor perspective, generates alpha or extra 
returns against a buy and hold strategy in the three countries of the Morgan Stanley Capital International (MSCI) Andean index. In order to make this proof, we will test the next active investment strategy:

1. To invest, at $t$, in the given Andean stock index if the investor expects to be in the low-volatility regime $(s=1)$ at $t+1$.

2. To invest in a risk-free asset (the 3-month U.S. Treasury bill) if the investor expects to be in the high-volatility regime $(s=2)$ at $t+1$.

We are using the MSCI index family by the fact the it is a well-known and widely used benchmarking company for investment purposes (Bodie, Kane, Marcus, 2014, Maggin, Tuttle, Pinto, \& McLeavey, 2007). The Global Industry Classification Standard used by MSCI (2018b), leads to a proper country and industry classification and aggregation method for the management of internationally diversified portfolios. Also, we decided to test the use of MS-GARCH models in the countries of the Andean region because these countries have shown an over-performance in relation to the other countries of the Emerging markets MSCI index. Another reason that lead us to make our tests in these countries is the aforementioned fact that little has been written about the use of MS models in that regions.

In order to perform our tests, we will run a weekly discrete event simulation from January $1^{\text {st }}$, 2000 to January $30^{\text {th }}$, 2019 (a total of 996 weeks) in which a theoretical investor will execute the aforementioned investment strategy.

Departing form these motivations and given our main interest herein, we structured the paper as follows: in the next section we will briefly discuss the MS-GARCH model and we will describe how has been used in the investment process. In the third section we will present a description and Statistical summary of the input data, along with the description of the pseudocode of our simulations. In the fourth section we present a review of our results and finally, in the fifth section, we present our conclusions and guidelines for further research.

\section{The MS-GARCH model and its use in active investing}

The MS-GARCH model used herein is the one with the functional form given in (6). In order to estimate it in a feasible way and as Haas, Mitnik y Paolella (2004) suggest, the MS-GARCH model must be inferred only from the residuals. Departing from the fact that the results in the present paper are among the first tests of the use of MS-GARCH models in the Andean stock markets, we assumed that the residuals must be calculated by detrending the return time series with the arithmetic mean $\left(\varepsilon_{t}=r_{t}-\mu\right)$. From the estimated MS models, we filtered and then used the smoothed probabilities (Gaussian and t-Student) of being in the $s$ regime at $t$. These were estimated as follows ( $\nu_{s}$ are the Markov-Switching degrees of freedom):

$$
\begin{gathered}
\xi_{s, t}=\frac{1}{\sqrt{2 \pi} \sigma_{s}} e^{-\frac{1}{2}\left(\frac{\varepsilon_{t}}{\sigma_{s}}\right)^{2}} \\
\xi_{s, t}=\frac{\Gamma\left(\frac{\nu_{s}+1}{2}\right)}{\sqrt{\left(\nu_{s}-2\right) \pi} \Gamma\left(\frac{\nu_{s}}{2}\right)}\left(1+\frac{\left(\frac{\varepsilon_{t}}{\sigma_{s}}\right)^{2}}{\left(\nu_{s}-2\right)}\right)^{-\frac{\nu_{s}+1}{2}}
\end{gathered}
$$

These smoothed probabilities, determined from the filtered probabilities (7) and (8) with Kim's (1994) algorithm, led us to a stable probability or mixing law $\pi_{s}$ of the next 
Log-Likelihood function to maximize in the estimation process $^{6}$ :

$$
L\left(r_{t}, \theta\right)=\sum_{t}^{T} \ln \left(\sum_{S=1}^{S} \pi_{s} \cdot \xi_{s, t}\right), \theta=\left[\sigma_{s}, \pi_{s}, \boldsymbol{\Pi}\right]
$$

In order to estimate the parameter vector $\theta$ in (9), we used the Viterbi (1967) maximization algorithm and from all the smoothed probabilities, we are interested in the observed values of $\xi_{s, t}$ at $t=T$ (the last date) and in the transition probabilities matrix $\Pi$. With these parameters, we estimated (forecasted) the smoothed probabilities $\xi_{s, t+1}$ of being in each regime at $t+1$ :

$$
\left[\begin{array}{l}
\xi_{s=1, t+1} \\
\xi_{s=2, t+1}
\end{array}\right]=\Pi\left[\begin{array}{l}
\xi_{s=1, t} \\
\xi_{s=2, t}
\end{array}\right]
$$

Given these probabilities and by following the related literature in time series analysis (Ang \& Bekaert, 2002b, Brooks \& Persand, 2001, Hamilton, 1989, 1990, 1994, Hauptmann et al., 2014, Kritzman et al., 2012), we focused our attention in the probability of the high-volatility regime $\left(\xi_{s=2, t+1}\right)$. With it, the investor was able to determine if she will be in the high-volatility regime at $t+1$, by using the next indicator function:

$$
s_{t+1}=\left\{\begin{array}{lll}
1 & \text { if } & \left.\xi_{(} s=2, t+1\right) \\
2 & \text { if } & \left.\xi_{(} s=2, t+1\right)>0,5
\end{array}\right.
$$

This function will be used in the pseudo algorithm that we will describe in the next section.

\section{Simulation method description}

\subsection{The pseudo algorithm of the simulations}

In order to perform our simulations of the investment process proposed herein, we are assuming a theoretical investor with a starting balance of USD 100,000.00 in her portfolio in which she will invest only in two type of assets:

1. The base 100 value, at January $7^{\text {th }}, 2000$, of the simulated country stock index. This value will be considered as the theoretical price of a theoretical zero tracking-error Exchange Traded Fund (ETF) of the simulated MSCI index.

2. The base 100 value, also at January $7^{\text {th }}, 2000$, of a theoretical mutual fund that pays the rate of the U.S. three-month Treasury bill.

By the fact that the present one is a first test in the Andean stock indexes, we assumed that the investor paid no trading costs or taxes during the weekly simulations. Complimentary to this assumption, the investor did not take into account currency risk (the simulated investor was a U.S. dollar based one) and there was no slippage risk neither in the ETF nor FX quote.

During the simulations, we assumed that the simulated trading account had two basic concepts or parts:

1. A portfolio or custody account in which the traded securities are held.

2. A cash account in which the proceedings that were not invested in a given security are also held.

Given these assumptions, we ran in each country and during the 996 weeks in the time period of interest, the next simulation pseudo algorithm:

\section{For week 1 to 999:}

\footnotetext{
${ }^{6}$ For further detail in the inference method, plase refer to Hamilton $(1989,1994)$.
} 
Revista Mexicana de Economía y Finanzas Nueva Época, Vol. 14 Primer Número Especial Aniversario, pp. 601-616

1. To value with a mark to market (at current market prices) process, the assets held in the custody account and also to balance the cash one.

2. To perform the MS (with either constant, $\mathrm{ARCH}$ or GARCH variance) given in (6).

3. To forecast the smoothed probability $\left(\xi_{s=2, t+1}\right)$ of being in the high-volatility regime at $t+1$.

4. If $s_{t+1}=2\left(\xi_{s=2, t+1}>0,5\right)$, then:

a. To invest in the risk-free asset (the U.S. Treasury bill fund). Else:

b. To invest in the risky asset (The simulated index ETF)

5. To value the portfolio and the trading account with a mark to market procedure.

\section{End For}

In the next section we present the observed results in our simulations that were made in each of the three Andean stock indexes. These simulations were made in 6 different scenarios in the step 2 of the previous pseudo algorithm:

1. The use of a homogeneous and symmetric Gaussian constant variance MS model (MS-Gaussian) at $t$.

2. The use of a homogeneous and symmetric t-Student constant variance MS model (MS-tStud).

3. The use of a homogeneous and symmetric Gaussian MS-ARCH model (MSARCHGaussian).

4. The use of a homogeneous and symmetric t-Student MS-ARCH model (MSARCHtStud).

5. The use of a homogeneous and symmetric Gaussian MS-GARCH (MSGARCHGaussian).

6. The use of a homogeneous and symmetric t-Student MS-GARCH (MSGARCHtStud).

Before we show these results, it is important to determine, with a proper Statistical test, if the time series of the three stock indexes of Table 1 should be modeled with MS models or not.

Table 1. The stock indexes and the risk-free asset used in the simulations.

\begin{tabular}{|c|l|c|c|}
\hline Refinitiv $^{\text {TM }}$ RIC@ & Data source & Index name & Country \\
\hline .dMICL00000PUS & Refinitiv $^{\mathrm{TM}}$ Eikon $^{\mathrm{TM}}$ & MSCI Chile index (USD) & Chile \\
\hline .dMICO00000PUS & Refinitiv $^{\mathrm{TM}}$ Eikon $^{\mathrm{TM}}$ & MSCI COLOMBIA index (USD) & Colombia \\
\hline .dMIPE00000PUS & Refinitiv $^{\mathrm{TM}}$ Eikon $^{\mathrm{TM}}$ & MSCI PERU index (USD) & Peru \\
\hline UST3MT $=$ RR & Refinitiv $^{\mathrm{TM}}$ Eikon $^{\mathrm{TM}}$ & 3-month U.S. Treasury bill & United States \\
\hline
\end{tabular}

\subsection{Statistical summary of the input data}

Given the previous description of the MS-GARCH models, we will use the weekly historical price time series of the MSCI (2018b, 2019) stock indexes and the U.S. 3-month Treasury bill rate shown in Table 1 . The return time series of the stock indexes were determined with the continuous time return method given in (2). The three time series start from June 6th, 1998 to January 31st (a total of 1,079 weeks). As previously mentioned, our simulations started at January 1st, 2000 and the returns of the previous weeks were used for estimation of the MS models. 
Table 2. Statistical summary (from June 1998 to January 2000) of the weekly returns of the simulated stock indexes and the rate paid by the risk-free asset (values in \%).

\begin{tabular}{|c|c|c|c|c|c|c|}
\hline Ticker & Min & 5 \% quantile & Mean & Standard deviation & 95 \% quantile & Max \\
\hline MSCICHLUSD & -0.2929 & -0.0478 & 0.0015 & 0.0329 & 0.049 & 0.2109 \\
\hline MSCICOLUSD & -0.2519 & -0.059 & 0.0024 & 0.0392 & 0.0624 & 0.1623 \\
\hline MSCIPERUSD & -0.2544 & -0.0564 & 0.0027 & 0.0389 & 0.0653 & 0.2468 \\
\hline USTBILL & -0.0002 & 0.000304 & 0.0373 & 0.0392 & 0.10538 & 0.12754 \\
\hline
\end{tabular}

Source: Own elaboration with data from Thomson Reuters (2018).

The Statistical summary (from June 1998 to January 2019) of the return time series is shown in Table 2. As noted, the three stock indexes have similar minimum values in the observed weekly returns, being the exception the Chilean case that has the lowest return of $-0.2929 \%$. A result of potential interest for the reader is the fact that the mean value of these three stock indexes is lower than the mean rate paid by the 3-month Treasury bills as risk-free asset.

In order to determine if the MS models are appropriate in the returns time series of the three stock indexes, we determined the single regime Gaussian and t-Student loglikelihood function (LLF) and then we applied Hamilton's $(1989,1994)$ filter in order to determine the constant variance, ARCH and GARCH MS models (also Gaussian and tStudent). With this LLFs we estimated the Akakike (1974) information criterion ${ }^{7}$ (BIC). The summary of the BIC of time series is shown in Table 3.

Table 3. The Akaike information criterion summary of the single and Gaussian and t-Student two-regime MS models used in our simulations from June 1998 to January

\begin{tabular}{|c|c|c|c|}
\hline \multicolumn{1}{c}{2000.} & Peru \\
\hline Stochastic process & Chile & Colombia & $-3,921.68$ \\
\hline Gaussian (one regime) & $-4,285.52$ & $-3,908.12$ & $-4,044.76$ \\
\hline t-Student (one regime) & $-4,439.53$ & $-4,037.02$ & $-4,095.14$ \\
\hline MS-Gaussian & $-4,492.07$ & $-4,050.09$ & $-4,100.19$ \\
\hline MS-tStud & $-4,488.84$ & $-4,062.26$ & $-4,104.54$ \\
\hline MSARCH-Gaussiano & $-4,494.7929\left[{ }^{*}\right]$ & $-4,039.25$ & $-4,096.57$ \\
\hline MSARCH-tStud & $-4,487.31$ & $-4,054.42$ & $-4,106.6368\left[{ }^{*}\right]$ \\
\hline MSGARCH-Gaussiano & $-4,493.92$ & $-4,067.2682\left[{ }^{*}\right]$ & $-4,104.90$ \\
\hline MSGARCH-tStud & $-4,482.84$ & $-4,062.32$ & $-4,2018$. \\
\hline
\end{tabular}

Source: Own elaboration with data from Thomson Reuters (2018).

As noted, it is appropriate to use MS models in the stochastic process of these three stock indexes. From all the MS models, the Gaussian MS-ARCH is the most suitable for the Chilean case and the Gaussian MS-GARCH for the Colombian and Peruvian one.

Departing from this, we have strong proofs about the use of MS models in each index. With this, we made a weekly recursive estimation of each model from January 2000 to January 2019. This as mentioned in step 2 of the simulation pseudo algorithm. The results of these estimations and those of the trading simulations are discussed in the next section.

\section{Simulations results}

As a departing point, we show, in Table 4, the performance summary of a passive investment made in each stock index and in the risk-free asset. As shown, the risk-free asset leads to a $38.38 \%$ accumulated return (a yearly $2.11 \%$ ). Also, the three stock indexes paid higher accumulated returns (alpha) with a $145.20 \%$ (7.99 yearly) paid by the Chilean index, $730.94 \%(40.23 \%)$ in Colombia, and 969.06

\footnotetext{
${ }^{7}$ The MSGARCH library does not allow to calculate ARCH or GARCH models with more than one lag in each term.
} 
Revista Mexicana de Economía y Finanzas Nueva Época, Vol. 14 Primer Número Especial Aniversario, pp. 601-616

Of special interest are the cases of the risk exposure metrics. Either the conditional value at risk $(\mathrm{CVaR})$ and the max drawdown show significant potential losses in the three stock indexes. This is a result that we expect to reduce by performing active trading activities with the simulation pseudo algorithm of section 2.1.

In order to test this last statement, we present in Table 5 the results of the active trading strategy made (with the each of the $6 \mathrm{MS}$ models of interest) in the Chilean stock index. As noted, the use of the t-Student constant MS and the Gaussian MS-GARCH variance models led to alpha generation in comparison to the passive strategy in the same stock market. From these two models, the use of the Gaussian MS-ARCH model led to the highest accumulated return with a $351.44 \%$ (19.34\% yearly) versus a $145.20 \%(7.99 \%)$ of the buy and hold strategy. Also, and as theoretically expected, the risk exposure is considerably lower than the passive strategy, being the use of the Gaussian MS-GARCH the case that lead to the lowest risk exposure with a $-6.88 \%$ of potential loss (measured with the Gaussian MS-ARCH model). Complimentary to this, the Sharpe ratio shows improvements against the one observed in the passive strategy. This is noted in practically all the six MS models.

Table 4. Performance summary of the passive or buy and hold investment strategy in the three stock indexes and the risk-free asset (data in \% with the exception of the

Sharpe ratio).

\begin{tabular}{ccccc}
\hline Ticker & Accumulated return & Mean return & Return Standard deviation & Max Drawdown \\
\hline MSCI Chile & 145.2050 & 0.0901 & 3.2291 & -34.6620 \\
MSCI Colombia & 730.9436 & 0.2128 & 3.7632 & -29.0246 \\
MSCI Peru & 969.0690 & 0.2381 & 3.9062 & -29.3625 \\
U.S. Treasury bill & 38.3854 & 0.0374 & 0.0393 & - \\
\hline Ticker & CVaR $\mathbf{9 5 \% )}$ & CVaR (98\%) & Sharpe ratio & \\
\hline MSCI Chile & -7.5621 & -10.6382 & 0.0076 & \\
MSCI Colombia & -8.9515 & -12.2807 & 0.0345 & \\
MSCI Peru & -8.8282 & -11.9637 & -0.043 & \\
U.S. Treasury bill & - & - & - & \\
\hline Source: Own elaboration with data from our simulations and from Thomson Reuters $(2018)$
\end{tabular}

Table 5. Performance results of the actively managed portfolios (from a U.S. dollar-based investor perspective) in the Chilean stock market with the use of Markov-Switching models.

\begin{tabular}{ccccc}
\hline $\begin{array}{c}\text { Markov-Switching } \\
\text { model scenario }\end{array}$ & $\begin{array}{c}\text { Accumulated } \\
\text { return }\end{array}$ & Mean return & $\begin{array}{c}\text { Return standard } \\
\text { deviation }\end{array}$ & Max Drawdown \\
\hline MS-Gaussian & 304.3449 & 0.1404 & 2.35 & -6.8837 \\
MS-tStud & 142.8021 & 0.0892 & 2.3695 & -10.0516 \\
MSARCH-Gaussian & 351.4477 & 0.1515 & 2.2433 & -6.8826 \\
MSARCH-tStud & 131.6221 & 0.0844 & 2.344 & -10.0567 \\
MSGARCH-Gaussian & 240.7838 & 0.1232 & 2.2545 & -14.8974 \\
MSGARCH-tStud & 296.9058 & 0.1385 & 2.2653 & -10.0541 \\
\hline Markov-Switching & $\mathbf{C V a R} \mathbf{( 9 5} \%)$ & $\mathbf{C V a R} \mathbf{( 9 8 \% )}$ & Sharpe rtio & Mean risky \\
model scenario & -4.9655 & -5.8791 & 0.013 & 96.9700 \\
MS-Gaussian & -5.3301 & -6.611 & 0.0085 & 96.9600 \\
MS-tStud & -4.8441 & -5.8324 & 0.0314 & 95.9600 \\
MSARCH-Gaussian & -5.3446 & -6.6101 & 0.0099 & 95.7400 \\
MSARCH-tStud & -5.2099 & -6.6896 & 0.019 & 89.1200 \\
MSGARCH-Gaussian & -5.0197 & -6.2081 & 0.0218 & 92.5500 \\
MSGARCH-tStud & astment \\
\hline Source: Own elaboration with data from our simulations and from Thomson Reuters $(2018)$.
\end{tabular}

By accepting that the Gaussian MS-GARCH model is the best for the active investing of a U.S. dollar-based investor in Chile, we believe that the observed improvements are because the MS-GARCH model is more accurate to forecast the probability of the highvolatility regime. With this, the fourth step in the simulation's pseudo algorithm lead to more suitable investment decisions at $\mathrm{t}$ and to a better performance and risk exposure 
values in the simulated portfolio.
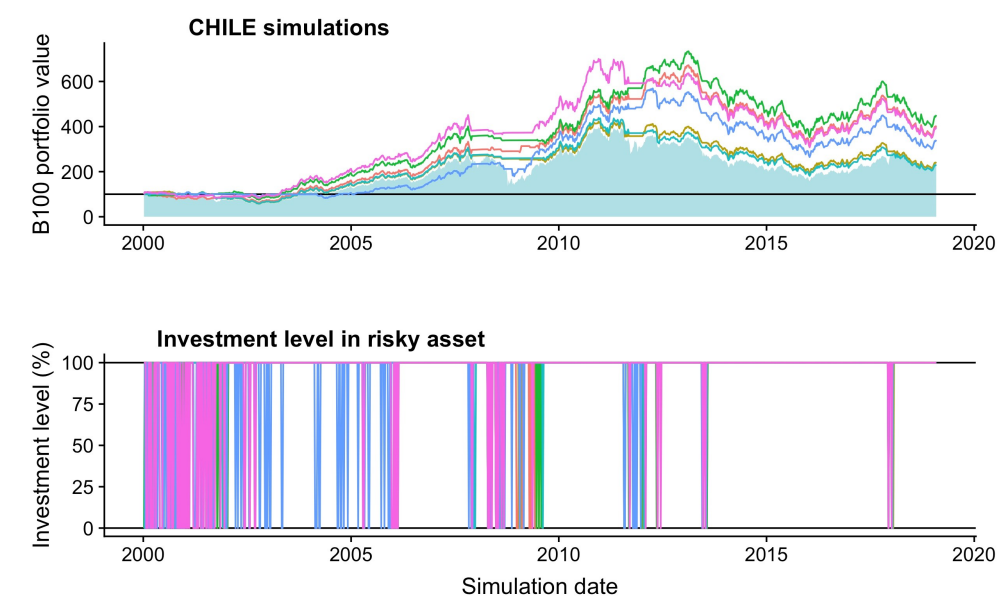

-MS-Gaussian - MSARCH-Gaussian - MSGARCH-Gaussian

Figure 1. Base 100 value of the simulated active managed portfolios in the Chilean stock market versus the passive or buy and hold investment strategy in that country. Source: Own elaboration with data from our simulations and from Thomson Reuters (2018).

Table 6. Performance results of the actively managed portfolios (from a U.S. dollar-based investor perspective) in the Colombian stock market with the use of Markov-Switching models.

\begin{tabular}{ccccc}
\hline $\begin{array}{c}\text { Markov-Switching } \\
\text { model scenario }\end{array}$ & $\begin{array}{c}\text { Accumulated } \\
\text { return }\end{array}$ & Mean return & $\begin{array}{c}\text { Return standard } \\
\text { deviation }\end{array}$ & Max Drawdown \\
\hline MS-Gaussian & 955.0516 & 0.2368 & 2.1647 & -7.8681 \\
MS-tStud & Not feasible & Not feasible & Not feasible & Not feasible \\
MSARCH-Gaussian & $1,236.0466$ & 0.2605 & 2.1173 & -7.7110 \\
MSARCH-tStud & 296.3706 & 0.1384 & 2.2519 & -11.1103 \\
MSGARCH-Gaussian & 417.1382 & 0.1651 & 2.7558 & -28.9105 \\
MSGARCH-tStud & 188.6814 & 0.1065 & 1.9005 & -10.7894 \\
\hline Markov-Switching & $\mathbf{C V a R ~ ( 9 5 \% )}$ & $\mathbf{C V a R ~ ( 9 8 \% )}$ & Sharpe rtio & Mean risky \\
model scenario & & & & investment \\
\hline MS-Gaussian & -4.6464 & -5.5010 & 0.0288 & 85.8800 \\
MS-tStud & Not feasible & Not feasible & Not feasible & Not feasible \\
MSARCH-Gaussian & -4.7034 & -5.5538 & 0.0719 & 87.9100 \\
MSARCH-tStud & -5.8443 & -7.5660 & 0.0214 & 89.2800 \\
MSGARCH-Gaussian & -6.7695 & -9.3602 & 0.0254 & 87.0400 \\
MSGARCH-tStud & -4.8102 & -6.8478 & 0.0140 & 75.7500 \\
\hline Source: Own elaboration & with data from 0 our simulations and from Thomson Reuters $(2018)$
\end{tabular}

Source: Own elaboration with data from our simulations and from Thomson Reuters (2018).

In order to proof this statement, we present in Figure 1 the historical performance of the six simulated active portfolios versus the passive or buy and hold strategy (shaded area). In the lower panel of this Figure we also present the historical investment level in the risky asset (stock index). As noted, in the most recent financial crisis episode (July 2007 to January 2009) ${ }^{8}$ the simulation led to a better performance in the Gaussian MSGARCH scenario. This happened by the fact that the simulated investor sold the index in most of that time period and bought the risk-free asset, leading to a lower risk exposure. This result is also observed during the European debt crisis of 2013 and the commodity price fall in 20013 and 2014.

\footnotetext{
${ }^{8}$ Corresponding to the U.S. financial crisis and its spillover effect to the Latin American stock markets.
} 

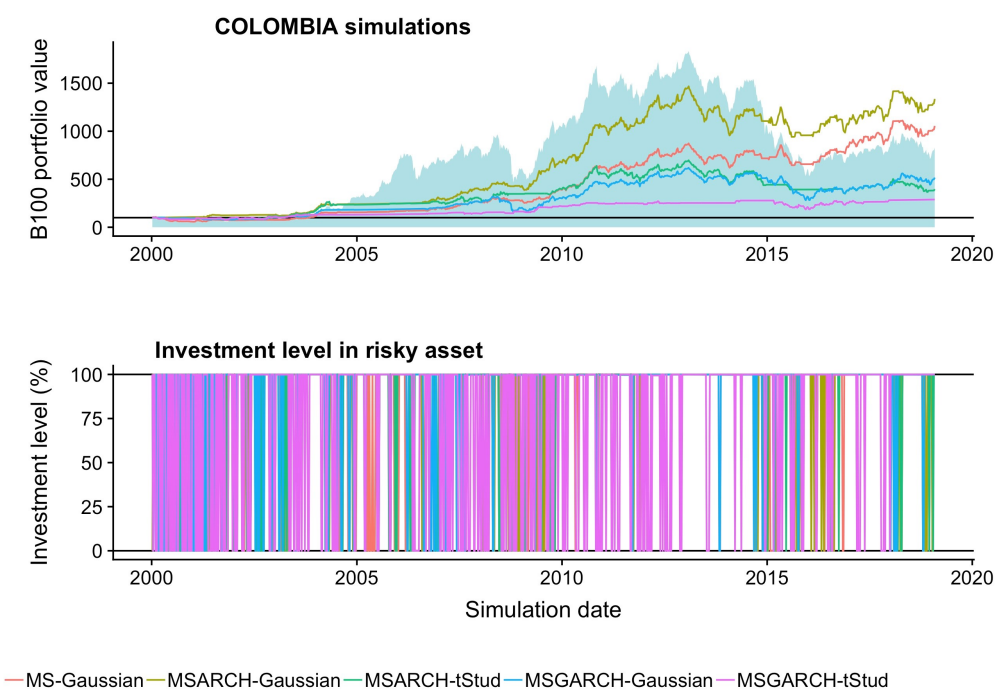

Figure 2. Base 100 value of the simulated active managed portfolios in the Colombian stock market versus the passive or buy and hold investment strategy in that country. Source: Own elaboration with data from our simulations and from Thomson Reuters (2018).

In a similar fashion to the previous country, we present in Table 6 the performance results for the Colombian stock market. In this case the Gaussian MS-ARCH model is the one that led to better performance results with an accumulated return of $1,236.37 \%$ ( $68.03 \%$ yearly). This return is higher than the $730.94 \%$ ( $40.23 \%$ yearly) of the passive strategy and also the use of this MS model led to better risk exposure metrics and meanvariance efficiency (Sharpe ratio). This is result is contrary to the observed in Table 3 in which the use of the Gaussian MS-GARCH (and not MS-ARCH) is better for time series fitting.

The performance result in the Colombian case is due, similar to the Chilean one, to the fact that the Gaussian MS-ARCH model is more sensitive to forecast the probability of being in the high volatility regime at $t+1$.

This is shown in Figure 2, in which the historical performance of the Gaussian MSARCH model shows a more stable and continuous trend during the simulations and an interesting performance during the 2015-2019 period. A period in which the passive strategy had a contraction. As noted, during those weeks, the simulated portfolio with the Gaussian MS-ARCH model was rebalanced from the risky asset to the risk-free one. 
Table 7. Performance results of the actively managed portfolios (from a U.S. dollar-based investor perspective) in the Peruvian stock market with the use of Markov-Switching models.

\begin{tabular}{|c|c|c|c|c|}
\hline $\begin{array}{l}\text { Markov-Switching } \\
\text { model scenario }\end{array}$ & $\begin{array}{l}\text { Accumulated } \\
\text { return }\end{array}$ & Mean return & $\begin{array}{c}\text { Return standard } \\
\text { deviation }\end{array}$ & Max Drawdown \\
\hline MS-Gaussian & 647.7677 & 0.2022 & 2.2406 & -8.8132 \\
\hline MS-tStud & Not feasible & Not feasible & Not feasible & Not feasible \\
\hline MSARCH-Gaussian & 457.2712 & 0.1727 & 1.9411 & -8.8116 \\
\hline MSARCH-tStud & 320.0473 & 0.1442 & 1.9712 & -9.1628 \\
\hline MSGARCH-Gaussian & 175.0547 & 0.1017 & 1.9897 & -13.5785 \\
\hline MSGARCH-tStud & 72.8231 & 0.055 & 1.407 & -8.3691 \\
\hline $\begin{array}{l}\text { Markov-Switching } \\
\text { model scenario }\end{array}$ & CVaR (95 \%) & CVaR (98\%) & Sharpe rtio & $\begin{array}{c}\text { Mean risky } \\
\text { asset investment }\end{array}$ \\
\hline MS-Gaussian & -4.8931 & -5.8094 & 0.0246 & 0.9194 \\
\hline MS-tStud & Not feasible & Not feasible & Not feasible & Not feasible \\
\hline MSARCH-Gaussian & -4.5394 & -5.5522 & 0.0383 & 0.9213 \\
\hline MSARCH-tStud & -4.7419 & -5.9544 & 0.0251 & 0.9031 \\
\hline MSGARCH-Gaussian & -4.9372 & -6.5737 & 0.016 & 0.8608 \\
\hline MSGARCH-tStud & -3.783 & -5.0911 & 0.005 & 0.8707 \\
\hline
\end{tabular}

Source: Own elaboration with data from our simulations and from Thomson Reuters (2018).
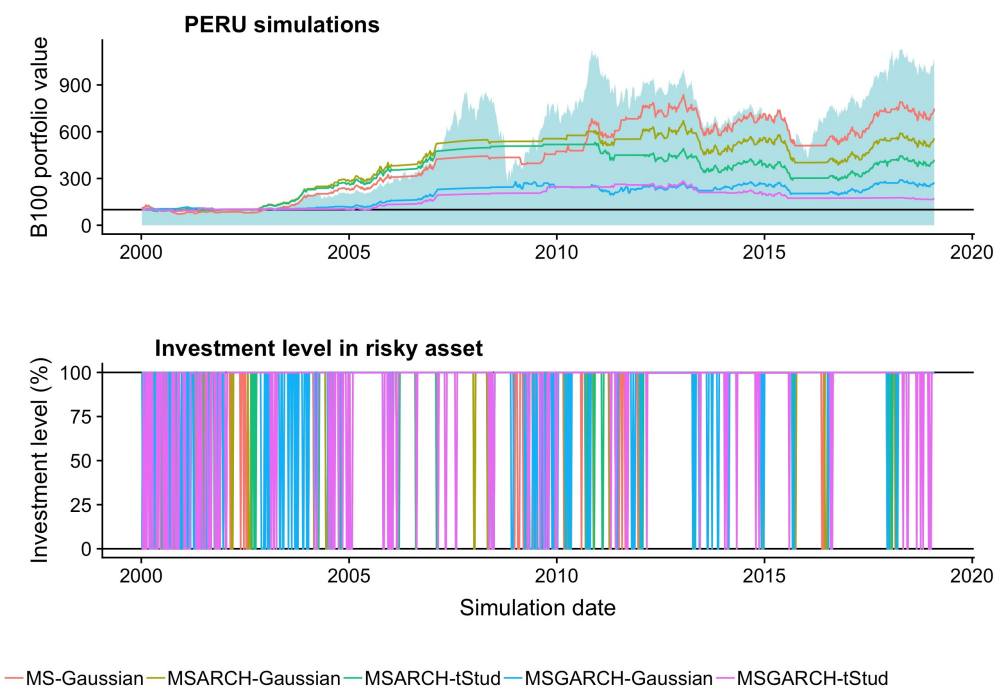

Figure 3. Base 100 value of the simulated active managed portfolios in the Peruvian stock market versus the passive or buy and hold investment strategy in that country. Source: Own elaboration with data from our simulations and from Thomson Reuters (2018).

As methodological note that will apply to the next stock index (Peru) it is noted in Table 5 that the t-Student constant variance MS model was not feasible in some weeks, given the estimation algorithm. Departing from this, we excluded this index from the simulations and show the legend "not feasible" in that Table.

Finally, we present in Table 6 the results of the simulations made in the Peruvian stock market. For this specific case, none of the simulated portfolios lead to a better result or alpha generation than the passive one. Given this result, we observe that it is better, for a U.S. dollar-based investor, to perform a passive investment strategy in this specific stock market.

Among the potential causes of this result is the fact that the Peruvian stock market is highly exposed to the performance of commodity prices (basic and precious metals) and also to the local financial industry. Therefore, the MS analysis should incorporate other exogenous factors, different to the historical return value of the stock index. As a 
Revista Mexicana de Economía y Finanzas Nueva Época, Vol. 14 Primer Número Especial Aniversario, pp. 601-616

DOI: https://doi.org/10.21919/remef.v14i0.425

corollary of our results, we observed that the use of an active investment strategy leads to alpha generation if the U.S. dollar-based investor uses a Gaussian MS-GARCH model in a weekly rebalanced portfolio in the Chilean market and if she does it with a Gaussian MSARCH model in the Colombian one. Also, the use of the MS, MS-ARCH or MS-GARCH models does not generate alpha or extra return from a passive (buy and hold) strategy in the Peruvian case.

\section{Conclusions}

Markov-Switching (MS) models were proposed by Hamilton $(1989,1990,1994)$, in order to model time series in which the stochastic process has an $s \geq 2$ number of regimes or states of nature. That is, the stochastic process is not generated with a unimodal or single-regime probability density function but with a s multimodal one that has s location (usually mean) and s scale (usually variance) parameters.

At the time of writing this paper, several applications of these models have been proposed and tested. Among the most related examples are the forecast of the probability that a given Economy will be in a recession regime at $\mathrm{t}+\mathrm{k}$. This along with the proper modelling of multivariate MS models for spillover effects among economies and financial markets. In a parallel way, there are tests about the use of MS models in the performance of Credit Default Swaps (CDS) and the contagion effect that their high-volatility regime has in other credit, stock or currency markets.

The Econometric application of these studies has been done in several developed countries such as the European Monetary Union countries or in specific countries such as France, Germany, Japan, Switzerland, the United Kingdom and the United States. Also there have been several applications and tests in developing countries such as Argentina, Brazil, China, Mexico, some Arab countries and South Africa. Departing from this bibliometric review, little has been written about the application of MS models in the stock markets of the Andean region. These countries are Emerging economies, given the current Morgan Stanley Capital International (MSCI) classification method, and had received no attention for MS modelling applied in investing.

The application of MS models in investment decisions is also an issue that has had little review in the current literature. The first works that study this use are the pioneering works of Brooks and Persand (2001) and Ang and Bekaert (2002a) or the extensions and particular tests of Kritzman, Page and Turkington (2012), Hauptmann et. al. (2014) or De la Torre, Galeana and Álvarez-García (2018). These last works test the use of MS investment strategies in portfolios and stock indexes of developed countries and only the work of De la Torre, Galeana and Álvarez-García (2018) makes a test in a developing stock market: Mexico.

Departing from this scant literature about the use of MS models for investment purposes in Emerging stock markets, we want to extend the current literature to the test of the use of two-regime MS models in the three countries that are members of the MSCI Andean stock index: Chile, Colombia and Peru (MSCI Inc., 2012). We also want to test these three countries by the fact that these are members also of the well-known MSCI Emerging markets index (MSCI Inc., 2018a). An benchmark that is also a member of the MSCI world index (MSCI Inc., 2018b). Our main interest herein was to test, from a U.S. dollar-based perspective, if the use of two-regime MS models in these three markets is appropriate for active investment.

Complementary to our main interest, we want to extend the literature about the use of MS models in active investing. We did this by using a time-varying variance with either the use of a MS autoregressive conditional heteroskedastic (MS-ARCH) variance or the use of a MS generalized autoregressive conditional heteroskedastic (MS-GARCH) one.

In order to test the usefulness of MS-ARCH or MS-GARCH models for active investing in these three countries, we assumed a two-regime (Gaussian or t-Student distributed) 
stochastic process in the three stock indexes. Departing from this, we tested the next investment strategy:

1. To invest in the simulated Andean stock index if the investor expects to be in the low-volatility or normal time period $(s=1)$ at $t+1$.

2. To invest in the U.S. risk-free asset if she expects to be in the high-volatility $(s=2)$ one.

By performing weekly discrete event simulations from January 2000 to January 2019 (a total of 996 weeks), we estimated each week (with data from June 1998) a MS, MS-ARCH or MS-GARCH model at $\mathrm{t}$ (with Gaussian or t-Student probability density function). With this estimation, we forecasted the probability of being in the high-volatility regime at $t+1$ and executed the previous investment strategy. Our results suggest that the use of the Gaussian MS-GARCH model in the Chilean stock market leads to the generation of alpha or extra returns and lead to the best performance in the simulations. Also, the Gaussian MS-ARCH model lead to the best performance and alpha generation in the Colombian market but, for the case of the Peruvian one it is preferable to perform a passive investment strategy, by the fact that the use of any of the MS models tested herein leads to a poorer performance than a buy and hold method.

Given the assumptions used in our simulations and the limitations found in these, we suggest extending the present research in the next aspects:

1. To perform the active management simulations by measuring the impact of trading costs, currency impact and slippage in the execution price.

2. To estimate the MS models with more than two regimes or states of nature and to develop investment strategies according to them.

3. To extend the MS-GARCH smoothed probability estimation to the case in which the transition probabilities are not fixed but time varying.

4. To test the present investment strategy in other Latin American markets from a local or non-U.S. dollar-based investor perspective

With the results that we present in this paper (the test about the use of MS-GARCH models) we hope to contribute to the literature about the use of MS models for investment decisions, along with our review of the benefits of investing actively in the stock markets of the Andean region.

\section{Referencias}

Ahmed, R. R., Vveinhardt, J., Štreimikiene, D., Ghauri, S. P., \& Ashraf, M. (2018). Stock returns, volatility and mean reversion in Emerging and Developed financial markets. Technological and Economic Development of Economy, 24(3), 1149-1177. https://doi.org/10.3846/20294913.2017.1323317

Akaike, H. (1974). A new look at the statistical model identification. IEEE Transactions on Automatic Control, 19(6), 716-723. https://doi.org/10.1016/J.CUB.2017.09.001

Alexander, C. (2002). Principal component models for generating large GARCH covariance matrices. Economic Notes, 31(2), 337-359. https://doi.org/10.1111/1468-0300.00089

Alexander, C., \& Kaeck, A. (2007). Regime dependent determinants of credit default swap spreads. Journal of Banking \& Finance, (32), 1008-1021. https://doi.org/10.1016/j.jbankfin.2007.08.002

Alvarez-Plata, P., \& Schrooten, M. (2006). The Argentinean currency crisis: A Markov-switching model estimation. Developing Economies, 44(1), 79-91. https://doi.org/10.1111/j.1746-1049.2006.00004.x

Ang, A., \& Bekaert, G. (2002a). International Asset Allocation With Regime Shifts. The Review of Financial Studies, 15(4), 1137-1187. 
Revista Mexicana de Economía y Finanzas Nueva Época, Vol. 14 Primer Número Especial Aniversario, pp. 601-616

Ang, A., \& Bekaert, G. (2002b). Regime Switches in Interest Rates. Journal of Business \& Economic Statistics, 20(2), 163-182. https://doi.org/10.1198/073500102317351930

Ang, A., \& Bekaert, G. (2002c). Short rate nonlinearities and regime switches. Journal of Economic Dynamics and Control, 26(7-8), 1243-1274. https://doi.org/10.1016/S0165-1889(01)00042-2

Areal, N., Cortez, M. C., \& Silva, F. (2013). The conditional performance of US mutual funds over different market regimes: do different types of ethical screens matter? Financial Markets and Portfolio Management, 27(4), 397-429. https://doi.org/10.1007/s11408-013-0218-5

Bodie, Z., Kane, A., \& Marcus, A. (2014). Investments global edition (10th ed.). New York, USA: Mc Graw-Hill.

Bollerslev, T. (1987). A Conditionally Heteroskedastic time series model for speculative prices and rates of return. The Review of Economics and Statistics, 69(3), 542-547.

Brooks, C., \& Persand, G. (2001). The trading profitability of forecasts of the gilt-equity yield ratio. International Journal of Forecasting, 17(1), 11-29.

Cabrera, G., Coronado, S., Rojas, O., \& Venegas-Martínez, F. (2017). Synchronization and Changes in Volatilities in the Latin American's Stock Exchange Markets. International Journal of Pure and Applied Mathematics, 114(1). https://doi.org/10.12732/ijpam.v114i1.10

Camacho, M., \& Perez-Quiros, G. (2014). Commodity Prices and the Business Cycle in Latin America: Living and Dying by Commodities? Emerging Markets Finance and Trade, 50(2), 110-137. https://doi.org/10.2753/ree1540-496x500207

Castellano, R., \& Scaccia, L. (2014). Can CDS indexes signal future turmoils in the stock market? A Markov switching perspective. CEJOR, 22(2), 285-305. https://doi.org/10.1007/s10100-013-0330-7

De la Torre, O., Galeana-figueroa, E., \& Álvarez-García, J. (2018). Using Markov-Switching models in Italian, British , U . S . and Mexican equity portfolios: a performance test. Electronic Journal of Applied Statistical Analysis, 11(2), 489-505. https://doi.org/https://doi.rg/10.1285/ i20705948v11n2p489

Dubinskas, P., \& Stungurienè, S. (2010). Alterations in the financial markets of the baltic countries and Russia in the period of Economic cownturn. Technological and Economic Development of Economy, 16(3), 502-515. https://doi.org/10.3846/tede.2010.31

Dueker, M. (1997). Markov Switching in GARCH Processes and Mean- Reverting Stock-Market Volatility. Journal of Business \& Economics Statistics, 15(1), 26-34.

Dufrénot, G., Mignon, V., \& Péguin-Feissolle, A. (2011). The effects of the subprime crisis on the Latin American financial markets: An empirical assessment. Economic Modelling, 28(5), 2342-2357. https://doi.org/10.1016/J.ECONMOD.2011.04.012

Engle, R. (1982). Autoregressive Conditional Heteroscedasticity with estimates of the variance of United Kingdom inflation. Econometrica, 50(4), 987-1007.

Girdzijauskas, S., Štreimikienė, D., Čepinskis, J., Moskaliova, V., Jurkonytė, E., \& Mackevičius, R. (2009). Formation of Economic bubles: cuases and possible interventions. Technological and Economic Development of Economy, 15(2), 267-280. https://doi.org/10.3846/1392-8619.2009.15.267-280

Glosten, L., Jaganathan, R., \& Runkle, D. E. (1993). On the Relation between the Expected Value and the Volatility of the Nominal Excess Return on Stocks. The Journal of Finance, 48(5), 1779-1801. https://doi.org/10.1111/j.1540-6261.1993.tb05128.x

Haas, M., Mittnik, S., \& Paolella, M. S. (2004). A New Approach to Markov-Switching GARCH Models. Journal of Financial Econometrics, 2(4), 493-530.

Hamilton, J. D. (1989). A New Approach to the Economic Analysis of Nonstationary Time Series and the Business Cycle. Econometrica, 57(2), 357-384.

Hamilton, J. D. (1990). Analysis of time series subject to changes in regime. Journal of Econometrics, 45(1-2), 39-70. https://doi.org/10.1016/0304-4076(90)90093-9

Hamilton, J. D. (1994). Time Series Analysis. Princeton: Princeton university press.

Hamilton, J. D., \& Susmel, R. (1994). Autoregressive conditional heteroskedasticity and changes in regime. Journal of Econometrics, 64(1-2), 307-333. https://doi.org/10.1016/0304-4076(94)90067-1

Hauptmann, J., Hoppenkamps, A., Min, A., Ramsauer, F., \& Zagst, R. (2014). Forecasting market turbulence using regime-switching models. Financial Markets and Portfolio Management, 28(2), 139-164. https://doi.org/10.1007/s11408-014-0226-0

Kanas, A. (2005). Regime linkages between the Mexican currency market and emerging equity markets. Economic Modelling, 22(1), 109-125. https://doi.org/10.1016/j.econmod.2004.05.003

Kim, C.-J. (1994). Dynamic linear models with Markov-switching. Journal of Econometrics, 60(1-2), 1-22. https://doi.org/10.1016/0304-4076(94)90036-1

Klaassen, F. (2002). Improving GARCH volatility forecasts with regime-switching GARCH. In Advances in Markov-Switching Models (pp. 223-254). https://doi.org/10.1007/978-3-642-51182-0 0

Klein, A. C. (2013). Time-variations in herding behavior: Evidence from a Markov switching SUR model. Journal of International Financial Markets, Institutions \& Money, 26, 291-304. https://doi.org/ $10.1016 / j$.intfin.2013.06.006

Kritzman, M., Page, S., \& Turkington, D. (2012). Regime Shifts: Implications for Dynamic Strategies. Financial Analysts Journal, 68(3), 22-39. 
Kutty, G. (2010). the Relationship Between Exchange Rates and Stock Prices: the Case of Mexico. North American Journal of Finance and Banking Research, 4(4), 1-12.

Lamoureux, C. G., \& Lastrapes, W. D. (1990). Persistence in Variance, Structural Change, and the GARCH Model. Journal of Business \& Economic Statistics, 8(2), 225-234. https://doi.org/10. 1080/07350015.1990.10509794

Lopes, J. M., \& Nunes, L. C. (2012). A Markov regime switching model of crises and contagion: The case of the Iberian countries in the EMS. Journal of Macroeconomics, 34, 1141-1153. https://doi.org/ $10.1016 / \mathrm{j} \cdot$ jmacro.2012.08.007

Ma, J., Deng, X., Ho, K.-C., \& Tsai, S.-B. (2018). Regime-Switching Determinants for Spreads of Emerging Markets Sovereign Credit Default Swaps. Sustainability, 10(2730), 1-17. https://doi.org/10. $3390 /$ su10082730

Maggin, J. L., Tuttle, D., Pinto, J., \& McLeavey, D. W. (2007). Managing Investment Portfolios: A Dynamic Process (John Miley and Sons Inc, ed.). Hoboken, USA.

Markowitz, H. (1959). Portfolio selection. Efficient diversification of investments. New Haven: Yale University Press.

Markowitz, Harry. (1952). Portfolio selection. The Journal of Finance, 7(1), 77-91. https://doi.org/10. $1111 / j \cdot 1540-6261.1952 . t b 01525 \cdot x$

Miles, W., \& Vijverberg, C.-P. (2011). Formal targets, central bank independence and inflation dynamics in the UK: A Markov-Switching approach. Journal of Macroeconomics, 33, 644-655. https://doi . org $/ 10.1016 / j . j m a c r o .2011 .04 .003$

Mouratidis, K., Kenourgios, D., Samitas, A., \& Vougas, D. (2013). Evaluating currency crises: A multivariate markov regime switching approach*. Manchester School, 81(1), 33-57. https://doi.org/ $10.1111 / j .1467-9957.2012 .02259 . x$

MSCI Inc. (2012). MSCI Andean Index (USD). Market cap indexes. Retrieved at April 24, 2019, from https://www.msci.com/documents/10199/a71ce44f-2f53-44eb-b40b-fcba0e5b5547

MSCI Inc. (2018a). MSCI emerging markets index. Indexes. Retrieved at May 12, 2018, from https:// www.msci.com/documents/1296102/1362201/MSCI-Emerging-Markets-Brochure-April-2018.pdf/9. e532b6f-5281-4e36-bdae-045328a2f $8 a c$

MSCI Inc. (2018b). MSCI Global Investable Market Indexes Methodology. Indexes. Retrieved at May 2, 2018, from http://www.msci.com/eqb/methodology/meth_docs/MSCI_Jan2015_GIMIMethodology_vf . pdf

MSCI Inc. (2019). End of day index data search - MSCI. Indexes. Retrieved at April 2, 2019, from https://www.msci.com/end-of-day-data-search

Nelson, D. B. (1991). Conditional Heteroskedasticity in Asset Returns: A New Approach. Econometrica, 59(2), 347. https://doi.org/10.2307/2938260

Parikakis, G. S., \& Merika, A. (2009). Evaluating volatility dynamics and the forecasting ability of Markov switching models. Journal of Forecasting, 28(8), 736-744. https://doi.org/10.1002/for.1135

Rotta, P. N., \& Valls Pereira, P. L. (2016). Analysis of contagion from the dynamic conditional correlation model with Markov Regime switching. Applied Economics, 48(25), 2367-2382. https://doi.org/ 10.1080/00036846.2015.1119794

Sharpe, W. (1963). A simplified model for portfolio analysis. Management Science, 9(2), 277-293.

Sharpe, W. (1964). Capital asset prices: A theory of market equilibrium under conditions of risk. The Journal of Finance, XIX(3), 425-442.

Sosa, M., Ortiz, E., \& Cabello, A. (2018). Dynamic Linkages between Stock Market and Exchange Rate in mila Countries: A Markov Regime Switching Approach (2003-2016). Análisis Económico, 33(83), 57-74. https://doi.org/10.24275/uam/azc/dcsh/ae/2018v33n83/sosa

Thomson Reuters. (2018). Thomson Reuters Eikon. Thomson Refinitiv Eikon login. Retrieved at December 10, 2018, from https://eikon.thomsonreuters.com/index.html

Viterbi, A. (1967). Error bounds for convolutional codes and an asymptotically optimum decoding algorithm. IEEE Transactions on Information Theory, 13(2), 260-269. https://doi.org/10.1109/TIT. 1967.1054010

Walid, C., Chaker, A., Masood, O., \& Fry, J. (2011). Stock market volatility and exchange rates in emerging countries: A Markov-state switching approach. Emerging Markets Review, 12, 272-292. https://doi.org/10.1016/j.ememar.2011.04.003

Walid, C., \& Duc Khuong, D. (2014). Exchange rate movements and stock market returns in a regimeswitching environment: Evidence for BRICS countries. Research in International Business and Finance, (31), 46-56. https://doi.org/10.1016/j.ribaf.2013.11.007

Zhao, H. (2010). Dynamic relationship between exchange rate and stock price: Evidence from China. Research in International Business and Finance, 24(2), 103-112. https://doi.org/10.1016/j.ribaf . 2009.09.001

Zheng, T., \& Zuo, H. (2013). Reexamining the time-varying volatility spillover effects: A Markov switching causality approach. North American Journal of Economics and Finance, 26, 643-662. https://doi. org $/ 10.1016 / j$.najef .2013.05.001 